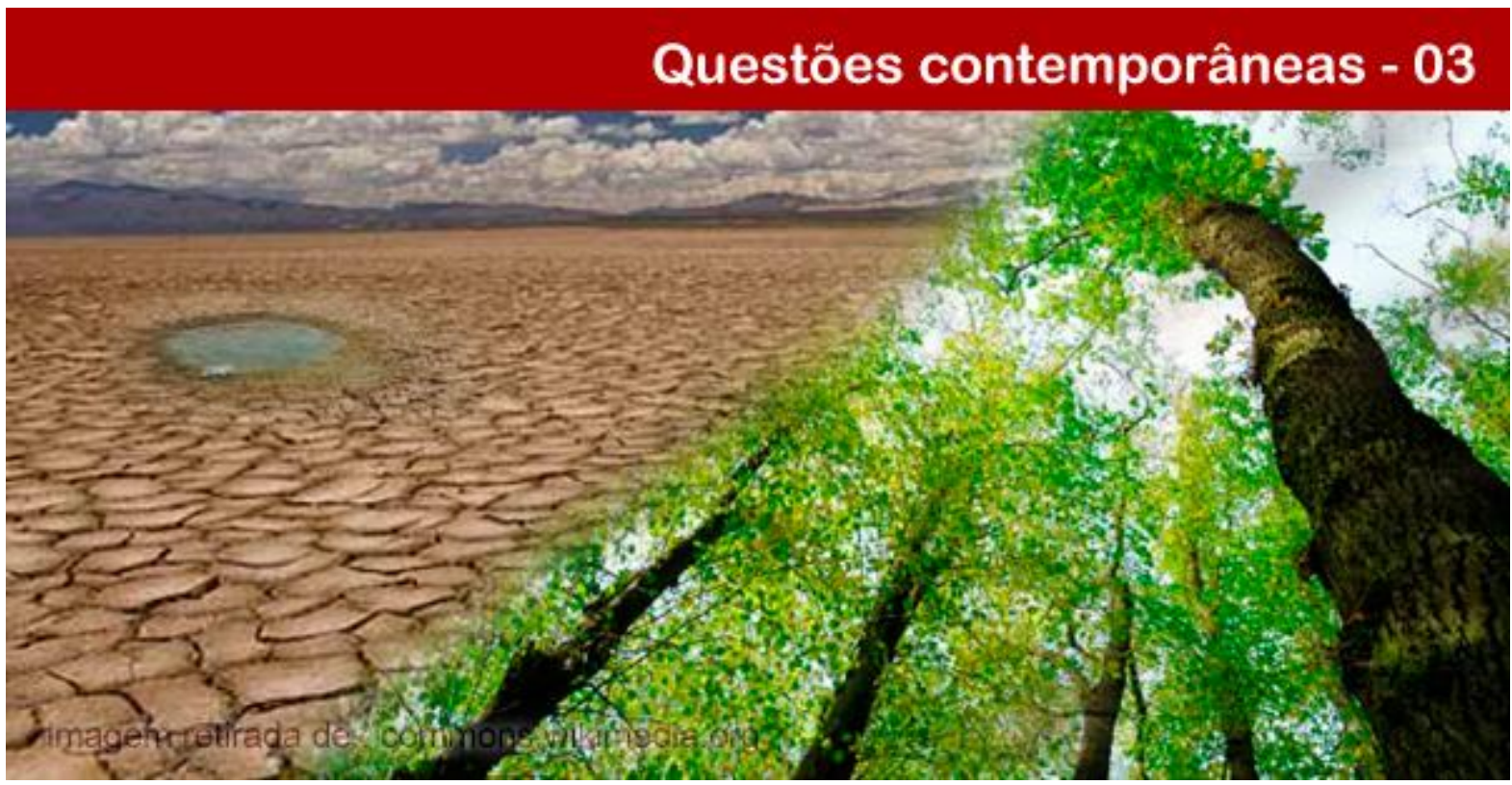

\title{
RESTAURAÇÃO DE ÁREAS NA PERCEPÇÃO DE PROPRIETÁRIOS RURAIS DO ENTORNO DA RESERVA SERRA DAS ALMAS
}

Maria da Penha Moreira Gonçalves

Engenheira Florestal. Doutoranda em Ciências Florestais pela Universidade Federal Rural de Pernambuco (UFRPE). E-mail: moreiraflorestal@hotmail.com.

Antônio Olavo Vieira das Chagas

Biólogo. Graduado pela Universidade Estadual do Ceará (UECE).E-mail: olavovieira25@gmail.com.br.

Resumo: Este trabalho teve por objetivo a caracterização e análise da percepção dos proprietários rurais do entorno da Reserva Natural Serra das Almas (RNSA) em relação ao processo de restauração de Áreas de Preservação Permanente (APPs) e Reserva Legal (RL). Foram trabalhadas comunidades do entorno da RNSA, Crateús - Ceará. Foram entrevistados proprietários rurais participantes das ações de restauração florestal de APP e RL em suas propriedades. Nas entrevistas, utilizou-se questionário quali-quantitativo e observações de campo em relação à situação das suas propriedades. Constatou-se que a população pesquisada é composta principalmente por idosos que obtém pequena parcela da sua renda advinda do trabalho na propriedade. Entre os fatores motivadores para realização dos trabalhos de restauração em suas propriedades foram citados a proteção da biodiversidade e o aumento da quantidade e qualidade da água, sendo a legislação ambiental um dos motivos de menor relevância para os mesmos. Conclui-se que na percepção dos produtores rurais a legislação é um dos motivos de menor relevância na tomada de decisão em restaurar áreas em suas propriedades, sendo os serviços ambientais, entre eles o aumento da quantidade e qualidade da água e a proteção da biodiversidade os mais importantes, podendo essa temática ser usada com sucesso em abordagens de educação ambiental no semiárido.

Palavras-chave: Meio ambiente. Recuperação. Semiárido.

\section{RESTORATION OF AREAS IN PERCEPTION OF OWNERS OF THE RURAL ENVIRONMENT THE SERRA DAS ALMAS NATURE RESERVE}

Abstract: The objective of this work was to the characterization and analysis of the perception of rural landowners in the vicinity of the Serra das Almas (RNSA) in relation to the restoration process of Permanent Preservation Areas (APP) and Legal Reserve (RL). Were worked communities in the vicinity of the RNSA, Crateús - Ceará. Interviews were held with rural landowners participants of the actions of forest restoration of APPs and RL in their properties. In the interviews, we used a questionnaire quali-quantitative and field

\section{POLÊM!CA $\mid$ LABORE (}

Polêmica - Revista Eletrônica da Uerj - Rua São Francisco Xavier, 524, $1^{\circ}$ andar

bloco D, sl.1001 • Tels.: +55 21 2334-4088/4087 • http://www.e-publicacoes.uerj.br/index.php/polemica/index http://www.labore.uerj.br • laboreuerj@yahoo.com.br 
observations in relation to the situation of their properties. It was found that the studied population is composed mainly of elderly who gets a small portion of their income derived from work on the property. Between the motivating factors for the achievement of the restoration works on their properties were cited the protection of biodiversity and the increase in the quantity and quality of water and environmental legislation one of the reasons of less relevant to them. It is concluded in the perception of rural producers the legislation is one of the reasons of less relevance in decision making on restore areas on their properties, and the environmental services, among them the increase in the quantity and quality of water and the protection of biodiversity the most important, may this theme be used successfully in approaches to environmental education in the semiarid.

Keywords: Environment. Recovery. Semiarid.

\section{Introdução}

As florestas e demais formas de vegetação nativas são de grande importância para o equilíbrio ambiental e ecológico do planeta, promovendo à amenização do clima, a estabilidade geológica, a manutenção da biodiversidade, a ciclagem dos nutrientes entre outros serviços ecológicos e ambientais citados pelo código florestal brasileiro (BRASIL, 2012).

Ao longo da evolução, a humanidade vem modificando o ambiente em que vive, principalmente, no intuito de garantir sua sobrevivência. Essa realidade é ainda mais notável na região compreendida pelo semiárido brasileiro, onde a dependência dos recursos naturais se faz mais expressiva.

O semiárido não é exclusividade do Brasil, sendo encontradas regiões com essas características em vários países do mundo, inclusive na América do Sul. No Brasil, o semiárido é constituído por uma área de $969.589,4 \mathrm{Km}^{2}$, abrangendo diversos Estados do Nordeste e Minas Gerais, sendo considerado o mais populoso do planeta e com as condições de vida mais precárias (MALVEZZI, 2007).

Nesse contexto de aridez, a vegetação exerce um papel fundamental na recarga e manutenção das fontes hídricas e na proteção do ambiente como um todo, já que durante o período das chuvas, a vegetação com folhas ameniza o impacto da água e a perda de solo e, na época da estiagem, as folhas fenadas alimentam os animais (ARAÚJO et al., 2011; DUQUE, 2004). A retirada da vegetação, principalmente das áreas protegidas por lei nas propriedades, impacta negativamente em diversos aspectos hídricos e edáficos, causando ainda a diminuição ou mesmo perda da biodiversidade dos sistemas agrícolas.

Assim como nos demais ambientes do país, no semiárido, o ser humano vem interagindo com os ecossistemas locais de forma insustentável (ARAÚJO et al., 2011), seja por falta de conhecimentos ou mesmo por falta de opção frente as dificuldades

\section{POLÊM!CA $\mid$ LABORE}


socieconômicas enfrentadas na região. Com isso, observa-se atualmente uma mudança de paradigma econômico na sociedade, já que o recurso natural, antigamente farto, tem se tornado cada vez mais escasso, devendo-se levar em conta sua possível exaustão. Assim, diversas leis têm surgido no intuito de racionalizar o uso da natureza, principalmente dentro das propriedades rurais particulares.

Uma das principais legislações brasileiras de determinação do uso da vegetação nativa é o código florestal, que foi alvo de grandes discussões nos últimos anos e esteve recentemente passando por mudanças que precisaram ser incorporadas à realidade das propriedades rurais. Esse código legisla sobre a obrigação de se preservar áreas sensíveis e de se manter uma parcela da vegetação nativa no interior das propriedades rurais. São as chamadas Áreas de Preservação Permanente (APPs) e área de Reserva Legal (RL) (BRASIL, 2012).

Atualmente, está em vigor o Cadastro Ambiental Rural (CAR), um instrumento que se destina a definir as áreas de Reserva Legal e a avaliar o estado de conservação das Áreas de Preservação Permanentes, das áreas de vegetação remanescente, bem como a situação das áreas convertidas para uso alternativo do solo. Com esse instrumento, entre outras medidas, vem a obrigatoriedade de recuperação das áreas alteradas da Reserva Legal e/ou Área de Preservação Permanente (BRASIL, 2012).

Atenção especial no que se refere à conservação e recuperação de áreas deve ser dada às propriedades rurais que margeiam Unidades de Conservação (UCs), já que tais proprietários, quando conscientizados e regularizados ambientalmente, podem tornar-se parceiros importantes na sustentabilidade das ações conservacionistas. Sem a parceria dos mesmos, a efetividade da conservação dos recursos naturais nessas UC's fica seriamente comprometida.

De acordo com o exposto, esse trabalho objetivou a caracterização e análise da percepção dos proprietários rurais do entorno da Reserva Natural Serra das Almas (RNSA), em Crateús, Ceará, em relação ao processo de restauração de Áreas de Preservação Permanente e Reserva Legal.

\section{Material e Métodos}

\section{POLÊM!CA $\mid$ LABORE}


O presente trabalho foi desenvolvido em todas as propriedades rurais do entorno da RNSA que foram incluídas no programa de restauração de áreas APPs e RL do projeto No Clima da Caatinga, desenvolvido no município de Crateús, CE, pela Associação Caatinga. Foi, assim, realizada a pesquisa em 14 propriedades rurais, no ano de 2012, sendo estas pertencentes à bacia hidrográfica do Rio Poti. A Reserva Natural Serra das Almas é reconhecida, pela UNESCO, como Posto Avançado da Reserva da Biosfera por abrigar uma representativa área de caatinga, protegendo uma área de 6.146 hectares.

Os proprietários rurais selecionados no entorno da Reserva para a presente pesquisa foram os participantes de ações de restauração florestal de Áreas de Preservação Permanente e Reserva Legal. A pesquisa realizada com eles teve o intuito de avaliar as características dos proprietários, a forma de uso das propriedades, a percepção dos mesmos em relação ao conhecimento da legislação ambiental e a importância e benefícios da ação de restauração de APPs e RL em propriedades rurais. Para isso, foram realizadas entrevistas em campo com levantamento de informações através de um questionário orientativo com perguntas qualitativas e quantitativas, sendo dividido em três blocos de perguntas, como segue: Bloco 1: Dados sobre o proprietário; Bloco 2: Dados sobre a propriedade; Bloco 3: Conhecimento do produtor sobre os benefícios da restauração de APPs e RL e sobre a legislação ambiental pertinente ao assunto. As entrevistas foram realizadas por meio de conversa informal com o produtor, de forma que o mesmo se sentisse à vontade para expor suas opiniões.

\section{Resultados e discussões}

\section{Caracterização dos proprietários rurais}

Observou-se que o perfil de idade dos proprietários rurais pesquisados (Tabela 1) indica que a população rural é composta na sua maioria $(64,29 \%)$ por uma população acima de 55 anos, sendo metade em idade de aposentadoria (acima de 65 anos), apontando assim que os jovens estão permanecendo menos na zona rural.

Tabela - 1: Classes das idades dos proprietários rurais entrevistados, em percentagem, em pesquisa no entorno da Reserva Natural Serra das Almas, Crateús - CE.

\begin{tabular}{cl}
\hline Idade dos proprietários & $\mathbf{\%}$ \\
\hline$<\mathbf{2 5}$ & 0,00 \\
\hline $\mathbf{2 5} \leq \mathbf{3 5}$ & 0,00 \\
\hline
\end{tabular}

\section{POLÊM!CA $\mid$ LABORE}




\begin{tabular}{ll}
\hline $\mathbf{3 5} \leq \mathbf{4 5}$ & 14,29 \\
\hline $\mathbf{4 5} \leq \mathbf{5 5}$ & 21,43 \\
\hline $\mathbf{5 5} \leq \mathbf{6 5}$ & 14,29 \\
\hline $\mathbf{6 5 5}$ & 50,00 \\
\hline
\end{tabular}

Geralmente os jovens têm saído da zona rural em busca de colocações no mercado de trabalho urbano, ficando a população rural composta principalmente por aposentados. Várias pesquisas vêm apontando essa tendência na população rural, onde a migração dos jovens é cada vez mais frequente não apenas nas zonas rurais do semiárido como também em outras regiões brasileiras (WINCK et al., 2013).

De acordo com Peripolli e Zoia (2011), as pesquisas indicam que cada vez mais os jovens trocam o campo pela cidade. Este fato evidencia um problema, que começa a se fazer presente em relação ao futuro da juventude rural, tais como a sobrecarga do mercado de trabalho na zona urbana, o desaparecimento da agricultura familiar, a falta de mão-de-obra no campo, entre outras.

Em relação ao grau de escolaridade dos proprietários rurais, 57,14\% responderam que possuem apenas o $1^{\circ}$ grau incompleto, que se refere ao ensino fundamental. Outros 14,29\% nunca estudaram e 21,43\% possuem o nível superior. Dessa forma, observou-se que apesar de uma percentagem considerável dos proprietários de terras possuirem o nível superior, a maioria possui pouco grau de instrução acadêmica. Em outros estados do Nordeste essa realidade também pode ser observada, como no estudo de Oliveira et al. (2012), realizado no Estado do Paraíba, em que $70 \%$ dos agricultores da região não tiveram oportunidade de estudar, tendo um total de $80 \%$ que não concluíram o ensino fundamental. Esse mesmo autor chama atenção para esse fato poder ter contribuído para a manutenção de um modelo de produção agrícola baseado no uso intensivo do solo.

Mendes et al. (2012), analisando a percepção de proprietários rurais em termos de adequação ambiental da propriedade rural, também observou em sua pesquisa que a maioria dos produtores rurais possuiam apenas o ensino fundamental incompleto e com isso constatou que grande parcela de proprietários que possuem o $1^{\circ}$ grau incompleto são dos que frequentaram a escola para o aprendizado básico, ou seja, aprendem a ler, escrever e "fazer contas", deixando logo em seguida a escola para ajudar nas atividades rurais.

\section{POLÊM!CA $\mid$ LABORE}


Foi observado que em relação à participação em cursos de aperfeiçoamento na área agrária, metade dos proprietários rurais entrevistados já participou de algum curso dessa categoria, mostrando dessa forma uma preocupação desses proprietários em buscar conhecimentos para o bom manejo das atividades nas suas terras.

Em relação a residência na propriedade rural, foi constatado que apenas $57,14 \%$ dos proprietários de fato residem nas propriedades rurais estudadas. Esse fato mostra que uma parcela significativa dessa população utiliza a propriedade rural apenas para trabalho, usando a mesma como forma de obtenção de renda, não gerando vínculo de moradia.

Analisando a relação existente entre o grau de escolaridade e a residência na propriedade rural, observou-se que entre os proprietários que não residem no campo todos possuem algum grau de instrução. Já entre os que moram na zona rural, foi encontrado o valor de $25 \%$ para aqueles que não possuem qualquer grau de estudo. Portanto, essas observações demonstram que apenas os proprietários com algum nível de escolaridade é que passaram a migrar sua moradia da zona rural para a cidade, onde obtêm outras fontes de renda através da prestação de serviços urbanos.

Foi relacionado também o tamanho da propriedade com o uso da mesma como residência, observando-se que naquelas com área de até 20 ha, 100\% residem na propriedade, e a maior percentagem de não residentes nas suas propriedades são detentores de propriedades consideradas de tamanho médio, superiores a quatro módulos fiscais (320 ha) e inferiores a 15 módulos fiscais (1.200 ha) (BRASIL, 1993). Sendo os proprietários de grandes quantidades de terras detentores de maiores rendas, podem esses optar por uma vida com maior "comodidade" nos centros urbanos, como observado no presente estudo.

No que se refere à renda dos proprietários rurais pesquisados (Figura 1), 35,71\% desses ganham mais de cinco salários mínimos e 28,57\% declararam ganhar até 1 salário mínimo.

Figura - 1: Total de renda dos proprietários rurais do entorno da Reserva Natural Serra das Almas, Crateús CE.

\section{POLÊM!CA $\mid$ LABORE}




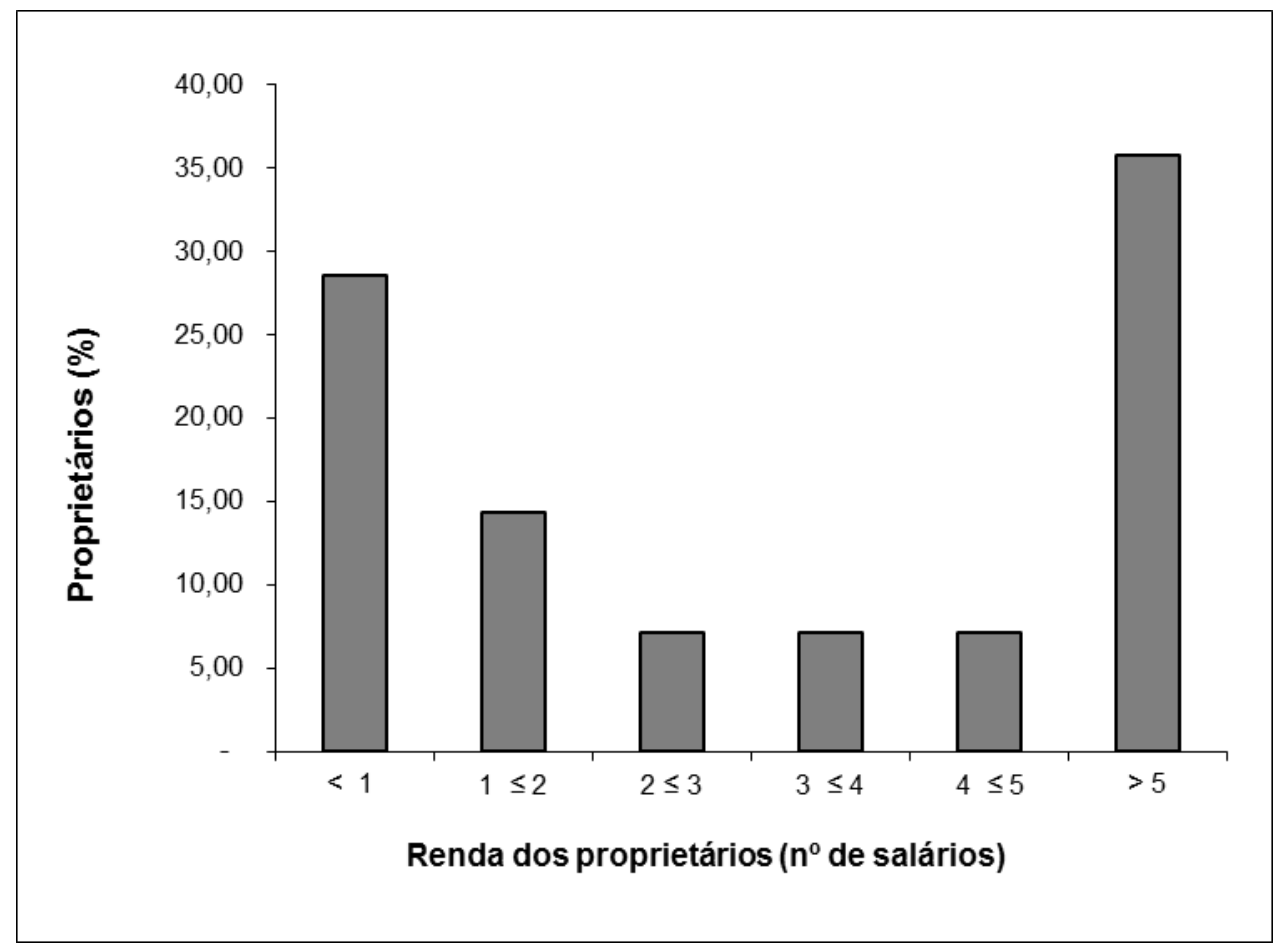

Quanto a renda gerada na propriedade rural, a maioria dos proprietários, 64,29\%, conseguem obter até 1 salário mínimo apenas com as atividades agrícolas. Assim, pode-se observar que a maioria dos entrevistados que possuem rendas superiores a 5 salários mínimos obtém essa renda através de outras fontes que não a propriedade rural, tendo essas outras atividades no meio urbano.

De acordo com Drumont et al (2000), além da ocorrência de estiagens severas, alguns dos agravantes na geração da pobreza no semiárido brasileiro estão relacionados ao sistema educacional e a assistência técnica ineficientes na região. Algumas dessas problemáticas foram igualmente observadas no presente trabalho, podendo assim reafirmar tais constatações.

\section{Caracterizações das propriedades rurais}

Quando analisado o percentual de propriedades por classe de área em hectares, é possível observar que houve uma predominância de propriedades com áreas superiores a 320 ha $(42,86 \%)$, que é característica de média propriedade rural no município de Crateús - CE, que possui como um módulo fiscal o valor de 80 ha (FAEC, 2012; Brasil, 1993). A propriedade rural de maior tamanho encontrada foi de 1448 ha e a de menor tamanho 18 ha.

\section{POLÊM!CA $\mid$ LABORE}


O Nordeste brasileiro foi apontado em diversas pesquisas como região de profundas desigualdades, não só em relação à distribuição de renda como também se tratando de divisão de terras.

Ramos e Sampaio (2007), realizando pesquisa com produtores rurais no município de Crateús, comentam que a estrutura fundiária nordestina pode ser caracterizada pelo alto grau de concentração de terras, sendo observados poucos donos com extensas terras (latifúndios) e um grande número de pequenos estabelecimentos (minifúndios), sendo esses últimos com áreas insuficientes para garantir o sustento adequado das famílias nas mãos de pequenos agricultores, que residem e trabalham nestes locais.

O mesmo autor citado no parágrafo acima ressalta que, para agravar a situação, a maioria das famílias que vivem em pequenas propriedades não tem a posse da terra, sendo posseiros e/ou meeiros, irregulares na terra onde vivem. Essa mesma situação fundiária também ocorre na presente pesquisa, que também foi realizada no mesmo município pesquisado pelo autor supracitado.

A divisão da propriedade por tipo de uso apontou como forma predominante o uso como manejo da mata nativa para pecuária (84\%). A agricultura, apesar de ser uma atividade comum na região, ocupou apenas $6 \%$ da área das propriedades rurais. Já as matas conservadas, onde não são introduzidos animais para pastejo ou outras atividades agrícolas, representaram 9\% em extensão de área.

A pecuária extensiva é predominante na região, onde os animais realizam o forrageio dentro da vegetação nativa, sendo que no período de estiagem, onde a mata nativa perde suas folhas e consequentemente a forragem, o sofrimento de tais animais é notável, resistindo poucos vivos, principalmente entre os bovinos. Nos períodos mais severos, esse fato é largamente noticiado nas mais diversas mídias do País.

Em relação ao uso da mata nativa para fins pecuários, o Ministério do Meio Ambiente (2011) considera o sistema agropastoril como o fator que maior pressão exerce sobre a cobertura vegetal do semiárido nordestino, sendo tal pressão variável na intensidade em função da localização, estrutura e tamanho dos remanescentes de mata nativa.

O excessivo consumo de espécies vegetais nativas por animais domésticos da pecuária nordestina tem ocasionado a diminuição drástica de populações da flora do semiárido. Espécies com frutos suculentos, como o umbuzeiro, assim como palmeiras importantes como

\section{POLÊM!CA $\mid$ LABORE}


a carnaúba, constituem um grupo susceptível à ação dos caprinos. Após a ingestão, os animais regurgitam e evacuam as sementes intactas nos estábulos, onde jamais darão origem a novas plantas adultas, além de ingerirem também as poucas plântulas que conseguem germinar na natureza (LEAL et al, 2003; CAVALCANTI et al., 2009).

A fauna nativa também acaba sendo extremamente prejudicada, já que evoluem junto com a flora e dependem desse como alimento e abrigo, sendo destruído o nicho de várias espécies e em paralelo com outras atividades humanas, levando-as a extinção.

Apesar do impacto negativo que a pecuária extensiva tem sobre o empobrecimento da vegetação nativa, o fato dessas propriedades estarem no entorno de uma Reserva Particular do Patrimônio Natural (RPPN) possibilita uma maior resiliência das mesmas no momento da restauração. A Reserva funciona como uma fonte de propágulos de diversidade genética e de espécies. Por outro lado, a falta da vegetação fora da Reserva, principalmente nas áreas protegidas por lei (APPs e RL), mostra-se limitante a movimentação da fauna, que usaria essas áreas como corredores ecológicos. Pode, assim, ser criada uma ilha de diversidade biológica na Reserva insustentável em longo prazo.

Silva (2013), analisando o caso das Reservas Privadas no semiárido no que diz respeito a conservação, aborda sobre a marginalização dos agricultores familiares do entorno dessas Reservas, citando que esses são encarados, muitas vezes, como destruidores da natureza. Dessa forma, como está mencionado na legislação, há a necessidade de integrar essas populações na gestão dessas unidades de conservação privadas, para que seja garantida a conservação dos recursos.

Em relação a agricultura comumente praticada na região, é considerada como itinerante, onde os agricultores desmatam, queimam e plantam por um curto período (em torno de dois ou três anos) e mudam para outras áreas repetindo a mesma prática, na expectativa de uma recuperação da capacidade produtiva dos solos (MENDES, OLIVEIRA, 2012).

A agricultura itinerante ou migratória vem reduzindo consideravelmente a biodiversidade do semiárido. Esse fato pode ser relacionado à intensidade com que vem sendo praticada essa atividade e ao pouco tempo de "repouso" que vem sendo dado à área entre um ciclo e outro de uso agrícola. Esse tempo não tem sido suficiente para que o solo se recupere

\section{POLÊM!CA $\mid$ LABORE}


do distúrbio causado e tão pouco a flora nativa, que acaba sendo reduzida a poucas espécies (DRUMOND et al, 2000; SIQUEIRA FILHO, 2012).

A mata conservada, observada nas propriedades pesquisadas, não foi reservada pelos produtores rurais com o intuito de conservação propriamente dita. São deixadas sem uso devido a impedimentos de naturezas diversas. A maioria dessas áreas se encontra situada em locais muito acidentados, como as escarpas encontradas na região, tendo dessa forma difícil acesso, que acaba desestimulando atividades agropecuárias nas mesmas.

A outra parcela das matas conservadas possui no seu sub-bosque espécies consideradas tóxicas aos ruminantes, como o popular tingui (Mascagnia sp), que é considerada a planta tóxica mais conhecida e difundida da região Nordeste (PACÍFICO DA SILVA et al., 2008). Assim, essas áreas são isoladas por longos anos, possibilitando a sua recuperação natural, sendo formadas florestas com maior nível de conservação no município. Porém, essas áreas não são representativas da totalidade de biodiversidade da região estudada, já que apresentam características peculiares à ocorrência de um número determinado de espécies devido sua natureza edafoambiental.

Quando relacionados os tipos de atividades destinadas nas propriedades com os seus respectivos tamanhos (Tabela 2), os dados revelam que:

a) em propriedades com área igual ou menor que 20 ha, 67,86\% foram ocupados com matas para pecuária, $32,14 \%$ com agricultura e sem ocorrência de mata conservada ou outras formas de uso;

b) em propriedades com área igual ou superior a 320 ha, 83,07\% foram ocupadas com matas para pecuária, $9,11 \%$ com mata conservada e $6,58 \%$ foram ocupadas com agricultura.

Tabela - 2: Relação entre tipo de uso da propriedade e as classes de tamanho de propriedades rurais do entorno da Reserva Natural Serra das Almas, Crateús - CE.

\begin{tabular}{cccccc}
\hline Uso da propriedade & \multicolumn{5}{c}{ Classes de tamanhos da propriedade (ha) } \\
\cline { 2 - 6 } & $\mathbf{2 0}$ & $\mathbf{2 1 - 1 2 0}$ & $\mathbf{1 2 1 - 2 2 0}$ & $\mathbf{2 2 1} \mathbf{- 3 2 0}$ & $\mathbf{3 2 0}$ \\
\hline Pastagem & 0 & 0,75 & 0 & 0 & 0,52 \\
\hline Agricultura & 32,14 & 12,03 & 36,84 & 0 & 6,58 \\
\hline Mata conservada & 0 & 0 & 11,02 & 0 & 9,11 \\
\hline Mata para pecuária & 67,86 & 81,95 & 47,53 & 0 & 83,07 \\
\hline Terras inaptas a uso & 0 & 5,26 & 4,61 & 0 & 0,72 \\
\hline
\end{tabular}

\section{POLÊM!CA $\mid$ LABORE}


Em propriedades de tamanhos superiores a 320 ha, a maior parte das áreas é destinada para pecuária de forma extensiva $(83,07 \%)$ e em mata nativa $(9,11 \%)$.

Nas propriedades de menores tamanhos, inferiores a 120 ha, não são conservadas áreas de matas nativas, sendo encontrada apenas a mata destinada a pecuária. A mata destinada a pecuária resguarda muito pouco da diversidade local, já que são vegetações mantidas na maioria das vezes em estágio inicial de sucessão.

Em relação ao tipo de atividade agropecuária exercida na propriedade, a bovinocultura se destacou com primeiro lugar no ranking geral seguida pela ovinocultura ou caprinocultura e em terceiro lugar a agricultura, composta principalmente por culturas como milho e feijão. Apesar de a atividade pecuária ser predominante na região estudada a menor percentagem de uso da propriedade se refere à pastagem cultivada $(0,5 \%)$, sendo que a maioria das pastagens usadas para alimentação desse rebanho é composta pela mata nativa (84\%). Os pastos plantados são na maioria das vezes pequenas capineiras para eventual complementação alimentar em casos especiais.

A descapitalização dos pecuaristas do semiárido e a dificuldade na obtenção de crédito impossibilitam possíveis investimentos no cultivo de pastagens, restando como alternativa o uso da mata nativa, podendo assim esses fatores estar associados às maiores pressões a esse tipo de cobertura vegetal nessa região. Porém, Araújo-filho (2014) ressalta que a caatinga tem apresentado uma maior intensidade de pastejo do que sua capacidade de suporte, sendo essa variável com a espécie animal e com o modelo de manipulação. Esse mesmo autor afirma que a capacidade de suporte para bovinos varia de 15 ha/UA/ano em caatinga nativa a 4,5 ha/UA/ano em caatinga raleada, e para ovinos e caprinos, as alterações vão de 12 a 3,5 ha/UA/ano para a caatinga nativa e caatinga raleada, respectivamente. Dessa forma, há a necessidade urgente de ser instalado um manejo sustentável dessas áreas nativas. Esses mesmos autores ressaltam que o resultado desse uso de forma desordenada se reflete numa forte e injusta competição com a fauna nativa, fato que está levando muitas espécies à extinção.

As áreas de mata nativa destinadas a pastagens apresentam ainda menor diversidade de espécies quando essas foram anteriormente desmatadas para fins agrícolas com a agricultura itinerante (GIULIETTE et al., 2004). De uma forma geral, as áreas de caatinga pastadas na região estudada são provenientes de cortes e queimas em vários ciclos agrícolas anteriores.

\section{POLÊM!CA $\mid$ LABORE}


Em alguns casos, a área é destinada à pecuária quando já não suporta mais cultivos agrícolas de tão esgotados são os recursos edáficos, chegando a ser observadas áreas com predomínio de uma ou duas espécies nativas arbustivo-arbóreas mais resistentes e com solo em fase avançada de degradação.

Quanto à finalidade da produção agropecuária foi constatado que 7,14\% é usada apenas para venda, $21,43 \%$ é usada apenas para subsistência, enquanto que $71,43 \%$ dos proprietários usam sua produção tanto para subsistência quanto para venda.

Percepção ambiental dos produtores rurais sobre a restauração de áreas de APPs e RL

Na Tabela 3 são apresentados os resultados sobre a percepção dos proprietários rurais no que diz respeito aos benefícios da restauração de APPs e RL. Os proprietários atribuíram grande importância aos serviços ambientais. Entre eles, a proteção da biodiversidade e o aumento da quantidade e qualidade da água foram os considerados como os de maior importância para os produtores rurais. Já o motivo "por que algum conhecido fez" e "uso de plantas medicinais" foram os itens de menor importância para os mesmos como motivação à ação de restauração.

Tabela - 3: Motivação para a prática da restauração florestal de APPs e RL de propriedades rurais do entorno da Reserva Natural Serra das Almas, Crateús - CE.

\begin{tabular}{lccc}
\hline \multirow{2}{*}{ Importância da restauração } & \multicolumn{3}{c}{ Categoria das respostas (\%) } \\
\cline { 2 - 4 } & 21,43 & $\mathbf{2}$ & $\mathbf{3}$ \\
\hline Cumprimento da legislação ambiental & 7,14 & 0 & 78,57 \\
\hline Por que algum conhecido fez & 50 & 0 & 92,86 \\
\hline Ter madeira disponível na propriedade & 71,43 & 0 & 50 \\
\hline Aumento na quant. e qual. da água & 64,29 & 0 & 28,57 \\
\hline Maior qualidade do ar & 42,86 & 0 & 35,71 \\
\hline Polinização agrícola & 64,29 & 0 & 57,14 \\
\hline Proteção dos solos & 14,29 & 0 & 35,71 \\
\hline Uso de plantas medicinais nativas & 78,57 & 0 & 85,71 \\
\hline Proteção da Biodiversidade & & 0 & 21,43 \\
\hline
\end{tabular}

Categorias: $1=$ grande importância, $2=$ medianamente importante, e $3=$ pouco importante.

A percepção de que a proteção da água é um dos serviços proporcionados pela natureza de grande importância já era esperado, já que a água é um dos fatores mais limitantes

\section{POLÊM!CA $\mid$ LABORE}

Polêmica - Revista Eletrônica da Uerj - Rua São Francisco Xavier, 524, $1^{\circ}$ andar bloco D, sl.1001 • Tels.: +55 21 2334-4088/4087 • http://www.e-publicacoes.uerj.br/index.php/polemica/index http://www.labore.uerj.br • laboreuerj@yahoo.com.br 
a sobrevivência no semiárido. Correlacionar a manutenção de florestas com produção de água torna-se um ponto indispensável em abordagens aos produtores rurais, já que esses têm sentido na prática o quanto a escassez desse recurso interfere na produtividade das suas propriedades e nas suas vidas como um todo. Sendo assim, atribuir à conservação e recuperação das matas ciliares a esse serviço pode facilitar a efetiva sensibilização de ações de educação ambiental na caatinga.

As áreas ciliares das propriedades rurais, na sua maioria, foram reduzidas a poucos indivíduos arbóreos, isolados nas margens do rio ou mesmo com o solo totalmente exposto. Como consequências disso, margens de rios desbarrancando, leitos de rios assoreados formando "bancos de areia", e percursos dos rios alterados foram observações notórias durante a realização do estudo.

Kawaichi (2009), avaliando a percepção de produtores rurais de distintas regiões brasileiras em relação aos benefícios da preservação de áreas naturais em suas propriedades, observou que a maioria dos proprietários aponta como serviço da natureza de maior importância a produção de água, sendo esse um dos principais motivos que os levariam a proteger as florestas.

Os produtores rurais trabalhados relacionaram também a conservação das matas à proteção da biodiversidade, atribuindo grande importância a esse serviço da natureza. Pôde ser percebida uma preocupação também em relação à diminuição da biodiversidade, principalmente em relação à fauna, sendo atribuído ao desaparecimento de várias espécies a caça predatória, que até esse momento tem sido uma das maiores pressões sofridas na caatinga.

De acordo com relatos dos produtores rurais, antes, os animais eram caçados prioritariamente para alimentação das famílias nos períodos de maior escassez de recursos (seca). Atualmente não há mais essa necessidade, já que existem vários programas sociais do governo beneficiando essas famílias. No entanto, a caça hoje é praticada de forma ainda mais intensa para alimentar um mercado clandestino de comercialização dessas carnes, que é voltado principalmente para pessoas de maior poder aquisitivo.

Drumond et al. (2012) igualmente atribuem ao desaparecimento de várias espécies da fauna da caatinga a caça predatória, comumente praticada na região desde a colonização e intensificada com o crescimento demográfico local.

\section{POLÊM!CA $\mid$ LABORE}


No que diz respeito a restauração de áreas para uso de plantas medicinais, foi pouco valorizado pelos produtores a restauração visando esse serviço. A importância das plantas medicinais nativas da caatinga tem sido exaltada por diversos autores, porém, atualmente, observa-se que tais espécies têm sido usadas em menor intensidade. Aliado a isso, a tradição de uso pouco difundida entre a nova geração pode resultar em esquecimento desse saber popular com o passar do tempo (GOMES et al, 2008; ALBUQUERQUE et al., 2010; FREITAS et al., 2012).

A legislação também foi citada, de uma forma geral, como um dos motivos de menor relevância para os produtores na sua tomada de decisão em restaurar áreas em suas propriedades. Esse resultado reflete a pouca fiscalização observada na região no intuito de cobrança do cumprimento das legislações pertinentes a manutenção de Áreas de Preservação Permanente e Reservas Legais. De acordo com os dados coletados, 78,57\% dos produtores rurais trabalhados conhecem, mas nunca tiveram contato, ou desconhecem fiscalizações ambientais na região trabalhada.

O Brasil, no que diz respeito à conservação ambiental, é possuidor de leis consideradas eficientes; caso fossem implementadas na prática, poderia se ter uma situação ambiental bem menos degradante. Assim, os problemas relacionados ao meio ambiente não serão resolvidos apenas com a criação teórica de áreas como APPs e RL. Para que haja uma efetiva conservação dos recursos naturais, é necessária também que haja uma mudança profunda de paradigmas da sociedade, inclusive da sociedade rural, iniciando pela formação de cidadãos conscientes de seus direitos e deveres para com o meio, através de eficientes processos de educação ambiental, difusão do mecanismo legal, além de uma ampla discussão com a sociedade antes da implementação das leis (BISPO, CARVALHO, 2006; JUCÁ, 2007).

\section{Conclusão}

É possível concluir que a permanência dos agricultores na zona rural local pode ser associada ao baixo grau de instrução dos mesmos e os jovens têm migrado cada vez mais do campo para as cidades, ameaçando assim o futuro das atividades tradicionais agrícolas na região.

O uso da pecuária extensiva dentro da mata nativa é considerado como principal atividade produtiva, sendo essa o principal agente de degradação ambiental, causando

\section{POLÊM!CA $\mid$ LABORE}


empobrecimento da flora, e ao mesmo tempo um dos principais motivos pelo qual ainda é possível observarem nas propriedades rurais da região fragmentos de vegetação nativa, mantidas para alimentação da pecuária.

Na percepção dos produtores rurais a legislação é um dos motivos de menor relevância na tomada de decisão em restaurar áreas em suas propriedades, sendo os serviços ambientais, entre eles, o aumento da quantidade e qualidade da água e a proteção da biodiversidade, os mais importantes, podendo essa temática ser usada com sucesso em abordagens de educação ambiental no semiárido.

\section{Referências}

ALBUQUERQUE, U. P.; et al. Caatinga: biodiversidade e qualidade de vida. Bauru: Canal 6, 2010. 120p.

ARAÚJO, I. P.; LIMA, J. R.; MENDONÇA, I. F. C. Uso e Degradação dos Recursos Naturais no Semiárido Brasileiro: Estudo na Microbacia Hidrográfica do Rio Farinha, Paraíba, Brasil. Revista Caminhos de Geografia, Uberlândia, v. 12, n. 39, p. 255-270, 2011.

ARAÚJO-FILHO, J.A. Proposta para a implementação do manejo pastoril sustentável da caatinga. Ministério do Meio Ambiente - Secretaria de Biodiversidade e Florestas. 2014, 135p. Disponível em: <http://www.mma.gov.br/publicacoes/biomas/category/61-caatinga〉. Acesso em: 02 de abr. 2015.

BISPO, W.; CARVALHO, J. Educação ambiental nas escolas: uma estratégia de mudança efetiva. 2006. Disponível em: < http://www.catolica-to.edu.br/portal/portal/downloads/docs_gestaoambiental/projetos20091/1-periodo/Educacao_ambiental_nas_escolas_uma_estrategia_de_mudanca_efetiva.pdf $\rangle$. Acesso em: $10 \mathrm{de}$ out. 2012.

BRASIL. Lei no 8.629, de 25 de fevereiro de 1993. Dispõe sobre a regulamentação dos dispositivos constitucionais relativos à reforma agrária. Diário oficial da união, Brasília, DF, 25 fev. 1993.

BRASIL. Lei $\mathrm{n}^{\circ}$ 12.651, de 25 de maio de 2012. Dispõe sobre a proteção da vegetação nativa. Diário oficial da união, Brasília, DF, 25 mai. 2012.

CAVALCANTI, N. de B.; RESENDE, G. M.; BRITO, L. T. L. Desenvolvimento de plantas de imbuzeiro (Spondias tuberosa Arruda) na região semi-árida do Nordeste. Rev. Bras. de Agroecologia, Porto Alegre, v. 4, n. 2, p. 186-190, 2009.

DRUMOND, M. A. et al. Avaliação e identificação de ações prioritárias para a conservação, utilização Sustentável e repartição de benefícios da biodiversidade do bioma Caatinga. In: Estratégias para o uso sustentável da biodiversidade da caatinga - Documento para discussão no GT - Estratégias para o Uso Sustentável. Seminário "Biodiversidade da Caatinga”, Embrapa Semi-Árido, Petrolina. Anais... 2000, 346p. Disponível em: 〈http://biodiversitas.org.br/caatinga/relatorios/uso_sustentavel.pdf〉. Acesso em: 12 de mar. 2017.

DRUMOND, M.A. et al. Bioma rico em diversidades. IHU on-line - Revista do Instituto Humanitas Unisinos, São Leopoldo, v.12, n. 389, p.13-17, 2012.

DUQUE, J. G. Solo e água do polígono das secas. $6^{\text {a }}$ ed. Fortaleza: Banco do Nordeste do Brasil, 2004. 334p.

\section{POLÊM!CA $\mid$ LABORE}

Polêmica - Revista Eletrônica da Uerj - Rua São Francisco Xavier, 524, $1^{\circ}$ andar

bloco D, sl.1001 • Tels.: +55 21 2334-4088/4087 • http://www.e-publicacoes.uerj.br/index.php/polemica/index http://www.labore.uerj.br • laboreuerj@yahoo.com.br 
FAEC. Tabela de módulos fiscais no Ceará. Disponível em: <www.faec.org.br〉. Acesso em: 02 de fev. 2012.

FREITAS, D. R. et al. Estrutura familiar e geração de renda em assentamentos rurais que desenvolvem atividade pecuária em Tomé-Açu e Paragominas no Nordeste e Sudeste paraense. Disponível em: <http://ainfo.cnptia.embrapa.br/digital/bitstream/item/60386/1/EstruturaFamiliar.pdf>. Acesso em: 20 de abr. 2012.

GOMES, E. C. S. et al. Plantas da caatinga de uso terapêutico: levantamento etnobotânico. Revista Engenharia Ambiental: Pesquisa e Tecnologia, Espírito Santo do Pinhal, v. 5, n. 2, p. 74-85, 2008.

GIULIETTI, A. M., BOCAGE NETA, A. L., CASTRO, A. A. J. F. Diagnóstico da vegetação nativa do bioma da caatinga. In: SILVA, J. M. C; TABARELLI, M.; FONSECA, M. T; LINS, L. V. (Orgs). Biodiversidade da Caatinga: áreas e ações prioritárias para a conservação. Brasília: MMA-UFPE, 2004. 47-90p.

JUCÁ, F. T. Marcos legais sobre Reserva Legal e Áreas de Preservação Permanente: uma estratégia para conservação dos recursos naturais. 2007, 45f. Monografia (Bacharel em Engenharia Florestal) - Universidade Federal Rural do Rio de Janeiro, Seropédica, 2007.

KAWAICHI, V. M. Uma análise das políticas públicas ambientais dos países e a adoção do Pagamento por Serviços Ambientais no Brasil. 2009, 91f. Monografia (Bacharel em Ciências Econômicas) - Escola Superior de Agricultura “Luiz de Queiroz”, Universidade de São Paulo, Piracicaba, 2009.

LEAL, I. R.; SILVA, A. V. da; TABARELLI, M. Herbivoria por caprinos na caatinga da região de Xingó: uma análise preliminar. In: LEAL, I. R. (Org.). Ecologia e conservação da Caatinga. Recife: Editora da Universidade Federal de Pernambuco, 2003. 695-715p.

MALVEZZI, R. Semi-árido: Uma Visão Holística. Brasília: Confea, 2007. 140p.

MENDES, C. J.; NEVES, C. U.; BERGER, R. Áreas de preservação permanente e reserva legal: Percepção dos proprietários rurais do município de Otacílio Costa, SC. Revista Floresta, v. 42, n. 4, p. 671-682, 2012.

MENDES, M. M. S; OLIVEIRA, M. E. Agricultura itinerante aspectos ambientais e sócio-econômico. Disponível em: <http://pt.scribd.com/doc/49754669/agricultura-itinerante-aspectos-ambientais-e-socioeconomico>. Acesso em: 04 de ago. 2012.

MINISTÉRIO DO MEIO AMBIENTE. Instituto Brasileiro do Meio Ambiente e dos Recursos Naturais Renováveis - IBAMA. Projeto de Monitoramento do Desenvolvimento dos Biomas Brasileiros por Satélite. Monitoramento do Desmatamento nos Biomas Brasileiros por Satélite - Monitoramento do Bioma Caatinga 2008-2009. Brasília, 2011

OLIVEIRA, R. R.; BARROS, J. D. S.; SILVA, M. F. P. Desertificação e degradação ambiental: percepção dos agricultores no município de Cachoeira dos Índios/PB. Revista Polêmica, v. 11, n. 2, 2012.

PACÍFICO DA SILVA, I. et al. Intoxicação natural pelas folhas de Mascagnia rigida (Malpighiaceae) em ovinos. Comunicação Científica. Arq. Inst. Biol., São Paulo, v. 75, n. 2, p.229-233, 2008.

PERIPOLLI, O. J.; ZOIA, A. O fechamento das escolas do campo: o anúncio do fím das comunidades rurais/camponesas. ECS, Sinop, v. 1, n. 2, p. 188-202, 2011.

RAMOS, L. R; SAMPAIO, J. L. F. Descobrindo os caminhos da convivência com o semi-árido no assentamento palmares em Crateús-CE. In: VII ENCONTRO DA SOCIEDADE BRASILEIRA DE ECONOMIA ECOLÓGICA, 2007, Fortaleza. Anais... Fortaleza: 2007.

SILVA, J. I. A. O. Conservação de Recursos Naturais no Semiárido e Desenvolvimento: Análise do Caso das Reservas Privadas. Revista Ambiente \& Sociedade, São Paulo, v. 16, n. 1, p. 79-98, 2013.

\section{POLÊM!CA $\mid$ LABORE}

Polêmica - Revista Eletrônica da Uerj - Rua São Francisco Xavier, 524, $1^{\circ}$ andar

bloco D, sl.1001 • Tels.: +55 21 2334-4088 / 4087 • http://www.e-publicacoes.uerj.br/index.php/polemica/index http://www.labore.uerj.br • laboreuerj@yahoo.com.br 
SIQUEIRA FILHO, J.A. (Org.). Flora das Caatingas do Rio São Francisco: História Natural e Conservação. Rio do Janeiro: Andrea Jakobsson Estúdio Editorial, 2012. 552p.

WINCK, A.C.; DALLA PASQUA, S.; FISCHER, A.; Gianezin, M. Processo sucessório em propriedades rurais na Região Oeste de Santa Catarina. Revista da Universidade Vale do Rio Verde, Três Corações, v. 11, n. 2, p. 115-127, 2013.

Recebido em: 08/04/2016.

Aceito em: 13/02/2017.

\section{POLÊM!CA $\mid$ LABORE}

Polêmica - Revista Eletrônica da Uerj - Rua São Francisco Xavier, 524, $1^{\circ}$ andar bloco D, sl.1001 • Tels.: +55 21 2334-4088/4087 • http://www.e-publicacoes.uerj.br/index.php/polemica/index http://www.labore.uerj.br • laboreuerj@yahoo.com.br 